\title{
Pilot study of pre-maxilla replacement and bone graft in a patient with lip and palate clefts: transforaminal relationship between up- per canines and bone graft
}

\author{
João Luis Carlini ${ }^{1}$, Danielle Del Santo², Kesia Keiko Asami
}

${ }^{1}$ Oral and Maxillofacial Surgery, Chief of Stomatology Departament, Professor at Federal University of Paraná, Staff of CAIF - Center for Integral Assistance of Cleft Lip and Palate Patients, Curitiba, Paraná, Brazil

${ }^{2}$ Dental Surgeon, School of Dental Medicine at Federal University of Paraná, Curitiba, Paraná, Brazil

\section{Abstract}

Objective: The aim of this study was to assess patients subjected to replacement surgery of the pre maxilla with bone graft, having as donor area the iliac crest and chin, and the relation with upper canines erupted in grafted areas. Materials and Methods: 54 records were evaluated from cleft patients that were under treatment at CAIF - Center of Attention to Clefts in Curitiba, PR, Brazil, both sexes, with unilateral and bilateral lip and palate clefts. Patients younger than fourteen years old, both sexes, that lost the surgical segment or did not continue the treatment at same welcoming institution, were excluded. The surgical segment average was 5.72 years. Results: Using both descriptive and chi-square statistics, we observed a statistically significant distinction regarding the eruption of upper canines in the region of secondary bone grafts when using iliac crest and chin grafts, which $62.8 \%$ of the sample that was treated with chin grafts happened to have an eruption of upper canines, and $37.2 \%$ were successful with iliac crest grafts (value-p 0.028). Conclusions: It is necessary to carry out a study with a larger sample size and where the samples are paired in order to confirm the superiority the iliac crest donor area as the gold standard for this surgical procedure.
Citation: Carlini J, Del Santo D, Asami K. (2015) Pilot Study of Pre Maxilla Replacement and Bone Graft in a Patient with Lip and Palate Clefts Transforaminal- Relationship between Upper Canines and Bone Graft. Dentistry 3000. 1:a001 doi:10.5195/d3000.2015.36

Received: July 24, 2015

Accepted: September 1, 2015

Published: September 29, 2015

Copyright: (C2015 Carlini J, Severo D, Asami K. This is an open access article licensed under a Creative Commons Attribution Work 4.0 United States License.

Email: kka12@pitt.edu

\section{Introduction}

Among congenital anomalies of the mouth, oral clefts stand out, ranging from those that may occur as an isolated or associated disorder to anomalies of varying degrees. During January, 1975 until December, 1994, we recorded 16,853 new cases of oral clefts in Brazil, having the southeast region contributed with $61 \%$ these news cases [1].

The clefted individuals have several problems associated with facial deformity including malocclusion, nasal deformity, problems with feeding, listening and speaking, and the association between clefts with other anomalies is evident.
These abnormalities affect the midface, occurring because the upper jaw bones do not fuse during the sixth and tenth week of intrauterine life [2]. Currently the classification of Spina is the most used to typify the lip and palate clefts [3]. After the primary reconstructive surgeries, lip repair and palatoplasty, becomes necessary 
surgery for correction the cleft alveolar ridge through bone grafts [4].

For the unilateral cleft patient, the secondary bone grafting surgery has been well described in the literature $[5,6]$. Clefts transforaminal patients are the most severely affected due to the absence of alveolar bone support in pre maxilla region, and absence of bone and soft tissue in hard palate region, leading to the projection of the pre maxilla, absence of eruption of the upper permanent canines, and absence of sealing lip $[7,8]$.

Having had a bone graft, or with the assistance of bone graft, changes in upper jaw growth are minimized because the majority of bone growth in the time of repositioning of pre maxilla, is already complete [9]. Treatment of pre maxilla in patients with bilateral clefts there are surgical procedures, such as complete refurbishment of the pre maxilla, promoting a better sealing lip [10], and the repositioning of pre upper jaw with autogenous bone graft [11].

Surgical treatment in bilateral clefts patients can have serious implication, because manipulating the pre maxilla can result in changes of bone growth in the region. There are controversies if the surgical intervention in pre maxilla should be performed before or after the complete facial growth [11].

Hedbuchel, Kypers-Jagtman, and Freihofer (1993) studies, demonstrated success with bone graft associated to upper jaw osteotomy and repositioning of pre maxilla, resulting in a well aligned and stabilized dental arch with a significant improvement in incisor inclination.

\section{SUBJECTS AND METHODS}

This study was experimental unit with 54 patients, unilateral or bilateral cleft lip and palate according to the classification of Spina [12], who were in treatment at Center of Attention to clefts lip and palate-CAIF, Curitiba-PR- Brazil. Clinical data were collected through medical and dental records, panoramic radiographs, in profile, upper occlusal and periapical the region of cleft.

Selected patients were older than 14 years old, an age that already set the functional position of the maxillary canines, and both sexes. Patients younger than 14 years age, both sexes, that lost the surgical segment or did not continue the treatment at same welcoming institution, were excluded.

The patients were submitted to treatment protocol of CAIF establishing assessment throughout the areas of dentistry, such as speech therapy, psychology, nursing, plastic surgery and pediatrics.

In orthodontic intervention breakers appliances were placed in the upper jaw to promote correction of atresia of upper jaw, and to improve the position of the pre maxilla. With this first step performed, the patient was referred to a team of Oral and Maxillofacial Surgery, where the molds of lower and upper arch were made. From the plasters models, surgery models with correct position of the pre maxilla were performed and the confection of surgical guides in autopolymerizing acrylic resin, for this new position.

The surgeries were performed under general anesthesia and tracheal intubation. After induction of anesthesia, lidocaine $2 \%$ with epinephrine 1:100.000 was infiltrated in the region to be surgically manipulated. 15 scalpel blades was used to vertically incise the margins of the cleft, extending laterally with intrasulcular incision one or two teeth apart from the area of the cleft, where alleviating incisions were made toward the back of the vestibule. The same procedure was performed on the opposite side, followed by the detachment of the mucoperiosteal flap. Vertical incisions were also made in the pre maxilla, followed by the detachment of the periosteum on the lateral and palatine portions on both sides. With the assistance of a reciprocating saw the bone situated on the posterior portion of the pre maxilla was segmented. The pre maxilla was anteriorly dislocated; the nasal mucus membrane was separated from the oral mucus membrane and the nasal floor was closed bilaterally using absorbable thread (polyglactin 4.0). Once the nasal floor was closed, the palatine mucus membrane was sutured with the remaining palatine mucus membrane existing in the pre maxilla, using absorbable thread (polyglactin 4.0). Next, the surgical guide was placed with steel thread no 0 on the screws that were placed on the pre maxilla and bilaterally on the area of the molars to reposition the pre maxilla.

In the donor area, the graft was removed from the iliac crest by the plastic surgeon. The chosen area is the internal (medial) of the crest. The removed block was monocortical, and with the use of a bone scoop, a large quantity of medullary bone was collected. After controlled the bleeding, a suture was performed as planned. The graft block was then prepared. The whole medullary part of the block was removed. The area corresponding to the bilateral cleft was totally filled in with medullary bone, which was collected through curettage and removed from the bone block. The remaining cortical bone plate of the iliac crest was 
then used for the placement of the pre maxilla on the stumps of the remaining upper jaw and supplying the containment of the particulate medullary bone in the area of the clefts.

The edges of the cortical block were placed on the distal extremity, corresponding to the alveolar process, with a $1.5 \times 7.0 \mathrm{~mm}$ screw and on the medial extremity, corresponding to the pre maxilla, with a $1.5 \times 7.0 \mathrm{~mm}$ screw. All the cutting edges that could traumatize the mucus membrane were removed with a spherical diamond drill bit in low revolution.

The whole grafted area was then covered with the mucoperiosteal flap with the assistance of alleviating incisions in the periosteum. The suture was performed without tension over the flap using

Table 1. Descriptive analysis of the number of patients and region of the donor area

\begin{tabular}{|c|c|c|}
\hline & Frequency & Percentage \\
\hline Iliac Crest & 24 & $44.40 \%$ \\
\hline Chin & 30 & $55.60 \%$ \\
\hline Total & 54 & $100.00 \%$ \\
\hline
\end{tabular}

a 4.0 nylon thread.

In the symphysis donor area, the incision was initiated $1.5 \mathrm{~cm}$ below the red line of the lower lip, cutting the mucus membrane and muscles, immediately directing the scalpel to the jaw bone. After detaching the periosteum, the osteotomy was performed with an appropriate design to adapt to the jaw defect with a number 701 conical tronca drill in low revolution. The suture of the donor area was performed in anatomic plans with two weeks.

polygalatine 4-0, keeping the external compressive dressings in the chin area to avoid labial ptosis and to offer the patient greater comfort.

The placement of the graft was made through miniplates and $1.5 \mathrm{~mm}$ titanium screws promoting the stability of the graft. A compressive dressing was placed over the area to reduce edema and control possible active bleeding points, kept for a minimum of three days. A regimen of intravenous antibiotics was performed with Cefazolin until the release of the patient (that occurs on the first day after the operation) and continued orally until the tenth day after the operation. Analgesia was done with Dipyrone and supplemented with Cetoprofeno.

Post-operation care included rigorous hygiene of the surgical area with brushing and use of mouth wash with Chlorhexidine $0.12 \%$. The follow up was done clinically and the sutures were removed after

Two months after the operation the surgical guide was removed and the stability of the pre maxilla was checked. The screws used in the placement of the graft were removed six months after the operation and, only after this procedure the patients were once again referred for orthodontic treatment.

The parameters used to evaluate the success of the treatment were based on periapical x-rays, done six months after surgery, the period during which the filling of the cleft with bone and the immobility of the pre maxilla are observed with a clinical exam. After six months the removal of the placement screws was scheduled, under local anesthetics, and the patient was referred to resume orthodontic treatment.

\section{RESULTS}

Fifty-four patients with an average age of 19.54 years old were selected based on inclusion criteria presenting a standard deviation of 6.790. The time elapsed from the surgery until the analysis of the medical-dental records had an average of 5.72 years, a standard deviation of 1.867. For the evaluation of the results, the non-parameter Chi-squared and the Fisher Test were used.

$33.3 \%$ of the patients were female, and $67.4 \%$ were male. In 33

Table 2. Comparative analysis between time of surgery and bone graft donor area

Surgical Follow-up

\begin{tabular}{|c|c|c|c|c|}
\hline Donor Area & Frequency & Average & $\begin{array}{c}\text { Standard Devia- } \\
\text { tion }\end{array}$ & P-value \\
\hline Iliac Crest & 24 & 5.1 & 1.4 & \multirow{2}{*}{0.033} \\
\hline Chin & 30 & 6.2 & 2.1 & \\
\hline Total & 24 & 5.7 & 1.9 & \\
\hline
\end{tabular}


patients it was verified that the type of cleft was the labiopalatal bilateral type, and 21 possessed unilateral lip and palatal cleft.

Through the evaluation of the panoramic and profile x-rays, six of the 54 patients evaluated presented with at least one of the permanent upper canines before the surgical procedure, corresponding to $88.9 \%$ of the presence of the same teeth included after the evaluation of the pre-surgery $x-$ rays. Besides the 6 aforementioned patients, 3 of the 54 patients, presented with the absence of both permanent canines, being that $94.4 \%$ of the sample presented with two included permanent upper canines in the area of the cleft subsequently operated.

In relation to the area originating from the bone graft, $44.4 \%$ iliac crest was used, and in 55.6\% of the patients chin graft was used (Table 2). After the operation, patient check-up and the evaluation of the post-procedure panoramic and profile x-rays, $11.1 \%$ of the patients maintained one of the canines included, $11.1 \%$ of the sample remained with both of the upper canines enclosed. In relation to the percentage of erupted upper canines in the area of the cleft, after the procedure of the placement of the bone graft and the replacement of the pre maxilla, $14.8 \%$ of the patients had at least one erupted canine, and $64.8 \%$ of the patients had both upper canines erupted in the area of the cleft. In this way, a succession was observed of approximately $80 \%$ of the patients of the sample.

Beginning with the statistical analysis carried out through the test of averages, 24 patients received an autogenous graft originating from the iliac crest donor area, obtaining a standard deviation of 1.4 , and 30 patients had the chin as the donor area, obtaining a standard deviation of 2.1 (Table 3). The P value for this case was 0.033 , concluding that there was significant statistical evidence of differences between the donor areas.

The group of patients that presented with eruption of the upper canines, the proportional test Qui-squared was applied, making it possible to verify statistical evidence between the percentages obtained.

Among the patients that were subjected to the reposition of the pre maxilla, and the filling in of the clefted area with iliac crest bone graft, $34.3 \%$ of the patients had upper canines, right and left, erupted. For the patients in whom autogenous bone graft was used, having the chin as the donor area, $65.7 \%$ of the patients presented with, after the abovementioned surgical segment, the two upper canines erupted $(p \leq 0.028)$ (Table 4).

\section{DISCUSSION}

The rupture of the alveolar bone, exactly at the height of the upper lateral incisors persists after the initial repair surgeries, maintaining the discontinuity of the upper arch [13]. This study of retrospective character evaluated the eruption of the upper canines in areas with an alveolar cleft, in carrier patients with unilateral and bilateral alveolar clefts, treated with chin and iliac crest bone grafts.

Many studies presented diverse techniques for the reconstruction of alveolar bone defects for these patients, autogenous bone or allogeneous sources being able to be used to provide a bone outline for the reparation of the defect. Among the autogenous donor areas most used are the iliac crest, chin, shin, costal arch and skullcap. The benefits of the bone graft in the treatment of cleft patients were well described, mainly when it concerned unilateral clefts. In the bilateral cleft patients, several particularities are noted, such as significant bone and soft tissue deficiency, exaggerated protrusion of the pre maxilla, frequent deviation of the upper dental midline, present malocclusion due to atresia of the upper jaw segments, mobility of the pre maxilla, pronounced buconasal fistulas. These factors damage the aesthetics and social inclusion, phonation and alimentation of these patients, limiting the orthodontic and prosthetic rehabilitations [5,14-16].

From an x-ray point of view, the periapical and occlusal $x$-rays allow the evaluation of the level of neoformation of the bone in the area of the bone graft [13], as they also allow the visualization of the upper canine eruption process.

Starting the surgery with bone graft in the area of the cleft, as much for patients with unilateral or bilateral clefts, it is expected that the upper canine erupts in the grafted bone, inducing the deposition of bone in the alveolar crest and increasing the vertical height of the upper jaw $[16,17]$. In our study we did not contemplate vertical height gain of the upper jaw; we limited ourselves verifying the viability of the eruption of the upper canines in the clefted area.

According to Cohen et al, the success or failure of the final result of the bone graft in the area of the cleft does not depend specifically on the donor area. Other factors influence the final result of the treatment, such as: morbidity, the viability of the autogenous bone, the type of bone, if it is cortical or spongy, and the biological behavior of the graft [5].

The iliac crest is the gold standard for grafts in cleft patients 
since it is a spongy bone which provides advantages, such as: the constant tissue growth of that bone, being remodeled more quickly than the cortical bone, rendering more viable the eruption of the teeth in the area of the

cleft. The chin graft also possesses advantages well described in literature, for example: easy access, less morbidity, similar embryonic origin, and quicker revascularization, with a tendency to keep greater post-operation bone volume when compared with the iliac crest graft [18].

Mish (2000) affirmed that autogenous bone grafts are osteogenic and capable of forming bone in the absence of undifferentiated mesenchymal cells. The grafted bone forms new bone in three different phases: osteogenesis, osteoinduction, and osteoconduction. He also observed that for the fact of the symphysis area having the same origin intramembranous as the upper jaw, there exists a quicker revascularization than the one of endochondral origin, as in the case of the iliac crest, having the advantage of minimal reabsorption and mobility of the graft, more premature vascularization, ambulation closer to the patient, no visible scar, abundant material, no secondary deformity and reduction of post-operation pain. In our study, we did not evaluate the post-operation conditions of the patients in agreement with the grafted area. Regarding the type of graft used and the eruption of the upper canines, we obtained better results with a patient on whom an intramembranous bone graft was used, the chin, possibly due to all the features of that type of bone origin and the receptor location.

Hedbuchel, Kuijpers-Jagtman and Freihofer performed a study in 1993 with 22 patients who presented with bilateral lip and palate cleft. In all their patients upper jaw osteotomy was performed with the stabilizing of the pre maxilla being that they used various types of grafts, such as: rib, iliac crest, chin, bone bank, and jaw bone. The average age of the patients of the study was 13.3 years old. The results obtained were satisfactory only having suffered the loss of one of the grafts. In our study, the patients were subjected to replacement of the pre maxilla with subsequent bone graft and we only used two types of bone, and the study group was composed of patients with both bilateral and unilateral transformed clefts. We also obtained satisfactory results in both groups, but with a greater statistical value for the group with chin bone graft.

Silva Filho and colleagues (2000), presented a study involving 50 patients $(32$ men and eighteen women) all with palatine gap and aged from eight to fifteen years old. All the patients were subjected to iliac crest bone graft for the filling of the palatine gap, and they were observed through x-rays for a period of one to five years. In $72 \%$ of the cases there was spontaneous eruption of the canines, in $6 \%$ of the cases there was a need for orthodontic traction, in the other $22 \%$ of cases there was movement of the teeth in question, but they had not erupted yet.

Our study included 54 patients, a sample similar to the previously cited study, being that $33.3 \%$ of the sample composed of male patients and $66.7 \%$ of female patients. Our patients were monitored through panoramic, profile, upper occlusal and periapical $\mathrm{x}$ rays of the upper canine area, in a period of seven days, three months, six months and twelve months following the operation. We obtained both of the erupted upper canines in $34.3 \%$ of the cases treated with iliac crest, and $65.7 \%$ of the cases treated with a chin graft.

Cohen and colleagues (1991) performed a study based on the experience of two plastic surgeons of the University of Illinois Hospital, Chicago. The patients were between nine and eleven

\begin{tabular}{|c|c|c|c|c|c|c|c|}
\hline \multicolumn{8}{|c|}{ Erupted Canine } \\
\hline & \multicolumn{2}{|c|}{1} & \multicolumn{2}{|c|}{2} & \multicolumn{3}{|c|}{ Total } \\
\hline $\begin{array}{l}\text { Donor } \\
\text { area }\end{array}$ & $\begin{array}{l}\text { Fre- } \\
\text { quency }\end{array}$ & $\begin{array}{l}\text { Col- } \\
\text { umn \% }\end{array}$ & $\begin{array}{l}\text { Fre- } \\
\text { quency }\end{array}$ & $\begin{array}{l}\text { Col- } \\
\text { umn\% }\end{array}$ & $\begin{array}{c}\text { Fre- } \\
\text { quency }\end{array}$ & $\begin{array}{c}\text { Col- } \\
\text { umn\% }\end{array}$ & $\begin{array}{c}\text { P- } \\
\text { value }\end{array}$ \\
\hline $\begin{array}{l}\text { Iliac } \\
\text { Crest }\end{array}$ & 4 & $50 \%$ & 12 & $34.30 \%$ & 16 & $37.20 \%$ & \\
\hline Chin & 4 & $50 \%$ & 23 & $65.70 \%$ & 27 & $62.80 \%$ & 0.028 \\
\hline Total & 8 & $100 \%$ & 35 & $100 \%$ & 43 & $100 \%$ & \\
\hline
\end{tabular}


years old at the time of the surgery, this age being similar to the age in our study, which was from eight to twelve years of age. The surgical technique used was similar in all the patients, only the type of graft being different: iliac crest or skullcap. The patients were monitored between 18 and 60 months and the results were satisfactory and without a significant difference between the two types of grafts [18]. In our study we compared two types of grafts, iliac crest and chin, with an average of 5.72 years of surgical follow-ups, being that we obtained satisfactory results in both groups, but not in all the cases, which affirms the objective of this research: eruption of the upper canines in the area of the bone graft bilaterally or unilaterally. For our research, we obtained a $37.2 \%$ success rate for the patients grafted with iliac crest, and a $62.8 \%$ success rate for the patients grafted with chin bone. 


\section{References}

1. Prevalência de fissuras orais de 1975 a 1994. Prevalence of oral clefts from 1975 to 1994, Brazil. Loffredo LCM, Freitas JASF, Grigolli AAG. Rev Saúde Pública vol.35 no.6 São Paulo Dec. 2001.

2. Prevalence of kinds of cleft lip and palate at a Pediatric Hospital in Northeast of Brazil. Cymrot M; Sales FCD; Teixeira FAA; Teixeira Jr. FAA; Teixeira GSB; Filho JFC; Oliveira NH. Rev. Bras. Cir. Plást. (Impr.) vol.25 no.4 São Paulo Oct./Dec. 2010.

3. A proposed modification for the classification of cleft lip and cleft palate. Spina V. Cleft Palate J. 1973 Jul;10:251-2. No abstract available. PMID: 4513915

4. Enxertia óssea alveolar: uma conduta para todas as fissuras alveolares. Roça GB, Freitas RS, Rodrigues LK, Busato LS, Canan L. Rev. Bras. Cir. Plást. 2010; 25(supl): 1-102.

5. Autogenous cancellous bone and marrow transplants. Boyne PJ. Clin Orthop Relat Res. 1970 Nov-Dec;73:199209. No abstract available. PMID: 4920990

6. Secondary bone grafting of alveolar clefts. A surgical/orthodontic treatment enabling a non-prosthodontic rehabilitation in cleft lip and palate patients. Abyholm FE, Bergland O, Semb G. Scand J Plast Reconstr Surg. 1981;15(2):127-40. No abstract available. PMID: 7041248

7. Alternative donor site for alveolar bone grafting in adults with cleft lip and palate. So LL, Lui WW. Angle Orthod. 1996;66(1):9-16. Review. PMID: 8678350

8. Implications and Treatment of Cleft Lip and Palate in Patients with an Autognenous Bone Graft. Rodrigues APGM; Castro HCBC; Reher P. Rev Bras de Cir Bucomaxilofac v. 10 n. 1 p. 91-6, 2010.

9. Surgical repositioning of the premaxilla with bone graft in 50 bilateral cleft lip and palate patients. Carlini JL, Biron C, Gomes KU, Da Silva RM. J Oral Maxillofac Surg. 2009 Apr;67(4):760-6. doi: 10.1016/j.joms.2008.07.013 . PMID: 19304031

10. Management of the prominent premaxilla in bilateral cleft lip and palate. Aburezq H, Daskalogiannakis J, Forrest C. Cleft Palate Craniofac J. 2006 Jan;43(1):92 PMID: 16405381

11. 0 impacto na qualidade de vida após o reposicionamento cirúrgico da pré-maxila em portadores de fissura lábio palatal bilateral - estudo de 50 casos. The life quality impact after surgical pre maxilla repositioning in patients with bilateral lip palatal cleft - study of 50 cases. Gomes KU; Rapoport A; Lehn CN; Denardin OVP; Carlini JL. Rev. Col. Bras. Cir. vol.35 no.6 Rio de Janeiro Nov./Dec. 2008.

12. An orthodontic and cephalometric study on the results of the combined surgical-orthodontic approach of the protruded premaxilla in bilateral clefts. Heidbuchel KL, Kuijpers-Jagtman AM, Freihofer HP. J Craniomaxillofac Surg. 1993 Mar;21(2):60-6. PMID: 8450075
13. Secondary bone graft and eruption of the permanent canine in patients with alveolar clefts: literature review and case report. da Silva Filho OG, Teles SG, Ozawa TO, Filho LC. Angle Orthod. 2000 Apr;70(2):174-8. Review. PMID: 10833007

14. Secondary bone grafting of residual alveolar and palatal clefts. Boyne PJ, Sands NR. J Oral Surg. 1972 Feb;30(2):87-92. PMID: 4550446

15. Bone grafting of alveolar clefts. Bertz JE. J Oral Surg. 1981 Nov;39(11):874-7. No abstract available. PMID: 7026745

16. 0 reposicionamento cirúrgico da pré-maxila como determinante da inclusão e integração social, em portadores de fissura lábio palatal bilateral: Estudo de 50 casos. Gomes, K.U. Dissertação (Mestrado em Ciências da Saúde) Hospital Heliópolis HOSPHEL São Paulo. 63 fls, 2008

1.

17. Elimination of the residual alveolar cleft by secondary bone grafting and subsequent orthodontic treatment. Bergland O, Semb G, Abyholm FE. Cleft Palate J. 1986 Jul;23(3):175-205. PMID: 3524905

18. Iliac versus cranial bone for secondary grafting of residual alveolar clefts. Cohen $\mathrm{M}$, Figueroa AA, Haviv Y, Schafer ME, Aduss H. Plast Reconstr Surg. 1991 Mar;87(3):423-7; discussion 428. PMID: 1998013

19. Late secondary autogenous bone grafting in cleft patients comparing mandibular (ectomesenchymal) and 
iliac crest (mesenchymal) grafts. Koole R, Bosker $\mathrm{H}$, van der Dussen FN. J Craniomaxillofac Surg. 1989 Dec;17 Suppl 1:28-30. PMID: 2606985

20. Implantes dentários contemporâneos. Misch, C. E. Segunda edição. São Paulo: Santos, 2000.

21. Secondary bone grafting and orthodontic treatment in patients with bilateral complete clefts of the lip and palate. Bergland O, Semb G, Abyholm F, Borchgrevink H, Eskeland G. Ann Plast Surg. 1986 Dec;17(6):460-74. PMID: 3548551

22. Reconstruction of alveolar cleft with allogenous bone graft: clinical considerations. Filho OGS; Ozawa TO; Bachega C; MA Bachega. Dental Press J. Orthod. vol.18 no.6 Maringá N ov./Dec. 2013. 